\title{
Dysphagia Rehabilitation: Similarities and Differences in Three Areas of the World
}

\author{
Marlís González-Fernández • Maggie-Lee Huckabee • \\ Sebastian H. Doeltgen · Yoko Inamoto • \\ Hitoshi Kagaya $\cdot$ Eichii Saitoh
}

Published online: 27 October 2013

(C) Springer Science + Business Media New York 2013

\begin{abstract}
Although the objective of dysphagia rehabilitation is the same, population needs, clinical practice patterns, availability of resources, and dysphagia research vary greatly around the world. The purpose of this review is to introduce the reader to the context in which dysphagia rehabilitation is practiced, to describe practice patterns, and to emphasize the dysphagia research being performed in three distinct regions of the world: North America, New Zealand and Australia, and Japan.
\end{abstract}

Keywords Dysphagia - Swallowing · Practice . Screening $\cdot$ Evaluation $\cdot$ Management

M. González-Fernández ( $\square)$

Department of Physical Medicine and Rehabilitation, Johns

Hopkins University School of Medicine, 600 North Wolfe

St. Phipps 186, Baltimore, MD 21287, USA

e-mail: mgonzal5@jhmi.edu

\section{M.-L. Huckabee}

Swallowing Rehabilitation Research Laboratory, New Zealand Brain Research Institute, 66 Stewart St., Christchurch 8011,

New Zealand

e-mail: maggie-lee.huckabee@canterbury.ac.nz

M.-L. Huckabee

Department of Communication Disorders, University of

Canterbury, 66 Stewart St., Christchurch 8011, New Zealand

\section{S. H. Doeltgen}

Discipline of Speech Pathology \& Audiology, Faculty of

Medicine, Nursing and Health Sciences, Flinders University,

Adelaide, SA 5161, Australia

e-mail: sebastian.doeltgen@flinders.edu.au

\section{Introduction}

Swallowing is a basic function required for life. Eating is not only practical (i.e. obtaining the nutrients necessary for survival) but also social. Sharing meals with family and friends is almost universally necessary for personal interactions. As such, the purpose of dysphagia rehabilitation is to ameliorate or eliminate the threat swallowing dysfunction is to physical health, quality of life, and participation in society.

Although the objective of dysphagia rehabilitation is the same, population needs, clinical practice patterns, availability of resources, and dysphagia research vary greatly around the world. The purpose of this review is to introduce the reader to the context in which dysphagia rehabilitation is practiced, to describe practice patterns, and to

\footnotetext{
Y. Inamoto

Faculty of Rehabilitation, School of Health Sciences, Fujita

Health University, Toyoake, Aichi, Japan

e-mail: inamoto@fujita-hu.ac.jp

H. Kagaya · E. Saitoh

Department of Rehabilitation Medicine I, School of Medicine,

Fujita Health University, Toyoake, Aichi, Japan

e-mail: hkagaya2@fujita-hu.ac.jp

E. Saitoh

e-mail: esaitoh@fujita-hu.ac.jp
} 
emphasize the dysphagia research being performed in three distinct regions of the world.

\section{The North American Perspective}

The evaluation and treatment of swallowing disorders is highly variable across North America. The availability of qualified professionals, and the needs and composition of the local population have a significant effect on the provision of care. A dearth of qualified professionals in remote areas of the continent is a challenge to overcome. Geographical variation in the incidence of diseases that are likely to cause dysphagia is also important. For example, one of the challenges faced in the United States is the geographic variation in the incidence of dysphagia after stroke $[1,2]$. The "stroke belt" encompasses the south east area of the country where stroke incidence is much higher than other areas. Thus, more trained professionals are necessary in those areas. Comparable with other countries in the developed world, the aging of the population is a challenge, as the need for swallowing rehabilitation services is likely to continue increasing. Overall, since the early establishment of dysphagia rehabilitation as a field approximately 40 years ago the quality and availability of trained clinicians has increased and knowledge of the normal physiology and possible treatment options has also increased. Nonetheless dysphagia rehabilitation continues to be an area in need of further research.

\section{Healthcare Funding}

Health care delivery is funded both publicly and privately in North America. The United States has a private insurance system in which each citizen is responsible for purchasing and maintaining their own healthcare insurance coverage. Most people in the US secure insurance through their employers. Both the federal and state governments provide coverage for people in financial hardship, people with disabilities, children, and the elderly. The coverage available to a particular person from public sources differs, depending on location of residence and personal circumstances. Generally speaking, the cost of traditional diagnostic and therapeutic intervention for dysphagia is covered by payers. The main difference between payers in the US is the duration of treatment covered. For example, Medicare (the federal program covering healthcare for retirees) has a therapy cap for physical therapy (PT) and speech-language pathology (SLP) services combined with the option of requesting an exception to therapy cap limits on the basis of therapist documentation of services as medically reasonable and necessary [3]. In contrast, premier private insurance will cover all treatment sessions needed as long as they are deemed medically necessary. A new healthcare law, the
Affordable Care Act, was approved in 2010 [4]. This law modifies the way healthcare is funded starting in 2014.

Canada has a national system composed of 13 government-based provincial and territorial health insurance plans that share basic standards of coverage. Thus, availability of services is not limited by the person's ability to afford medical care.

\section{Delivery of Care and Professional Qualifications}

Dysphagia rehabilitation is a relatively new field. One of the first papers on dysphagia rehabilitation was published in 1972 [5]. The first textbook on the topic was published in 1983 [6]. The American Speech-Language-Hearing Association (ASHA) published its first report on dysphagia in 1987, providing guidelines for clinical training of speechlanguage pathologists and for treatment intervention (updated) [7]. A similar statement was published in 1995 by the Canadian Association of Speech-Language Pathologists and Audiologists (CASLPA) [8]. The ASHA and CASLPA both have certification programs for speech language pathologists (SLPs), and SLPs progressively became the primary providers of dysphagia rehabilitation services. Currently, $91 \%$ of hospital-based speech language pathologists provide dysphagia rehabilitation services regularly [7]. Academic and professional organizations such as the ASHA and CASLPA have been instrumental in developing training guidelines. Since 1995 SLPs with specialty in swallowing disorders can opt to be certified as Board-Recognized Specialists in Swallowing (BRS-S).

Although SLPs provide the vast majority of dysphagia rehabilitation services in North America, multidisciplinary rehabilitation teams are often necessary to bring complementary expertise to the treatment of swallowing disorders. Physicians (otorhinolaryngologists, gastroenterologists, physiatrists, and radiologists) contribute to evaluation of swallowing (clinical and instrumental) and treatment interventions. Occupational therapists use their expertise on activities of daily living to improve feeding behavior and eating. Dieticians or nutritionists are also part of the team and provide recommendations to maintain appropriate caloric and nutritional intake when diet texture modifications or non-oral feeding is necessary.

\section{Diagnosis and Management}

Diagnosis and management of swallowing disorders are variable in North America. Availability of trained practitioners and resources are likely to be major contributors to this variability. Guidelines for evaluation and treatment have been developed by the main professional organizations in the field (ASHA, CASLPA). Within these guidelines there is great flexibility as to how evaluation and treatment are 
conducted in practice. A treatment algorithm or recommended approach to the dysphagic patient is not prevalent.

\section{Screening}

Screening for dysphagia is common in hospitals. In most hospitals, patients with neurologic disease (most prominently stroke) and with head and neck malignancies are screened routinely for swallowing dysfunction. The joint commission (the accreditation body for hospitals in the US) has included dysphagia as one of the core measures in the accreditation of stroke centers [9].

The clinical practitioner who performs the screening varies greatly; nurses, physicians, and SLPs most commonly perform this evaluation. The tools available for screening also vary greatly. Most screening tests combine a short evaluation of a patient's history and a water swallowing trial. Validated tools are often used for screening stroke patients. Table 1 provides a summary of validated tools and test characteristics.

\section{Assessment}

SLPs are mainly responsible for dysphagia assessment in North America. A clinical (or bedside) swallowing evaluation performed by SLPs is most commonly the first intervention in the diagnosis of swallowing disorders. In Canada, it has been reported that SLPs evaluated 71-99 \% of patients by clinical assessment $\left[10^{\bullet}, 11^{\bullet}\right]$.

There is high variability in the components of clinical swallowing evaluation but most include:

1. cranial nerve examination;

2. oral motor and sensory examination; and
3. oropharyngeal swallowing evaluation using several foods and liquids.

Mathers-Schmidt and colleagues reported that components of more than $90 \%$ of clinical swallowing evaluation were [12•]:

- patient history;

- assessment of vocal quality (pre/post swallow);

- adequacy of lip seal;

- adequacy of dentition;

- presence of volitional cough;

- judgment of efficiency of oral movements;

- structural and/or functional oral motor examination;

- judgment of pharyngeal delay;

- adequacy and/or strength of laryngeal excursion;

- patient perception of problem; and

- assessment of mental status.

Conversely, elements reported less frequently include (in descending order):

- assessment of speech function;

- assessment of language abilities;

- trials with compensatory techniques;

- assessment of sensory function;

- presence and/or strength of gag reflex;

- cervical auscultation; and

- indirect laryngoscopy.

McCullough et al. [13] had previously reported that elements of history, voice, oral motor function, and trial swallows were used by most SLPs but the specific elements differed compared with the aforementioned study.

It has been reported that most SLPs in the US use selfdeveloped or facility-developed assessment strategies (44\%), and that published peer-reviewed tools or

Table 1 Dysphagia screening tests

\begin{tabular}{|c|c|c|c|c|c|c|}
\hline Test & $\begin{array}{l}\text { Method of choice } \\
\text { for validation }\end{array}$ & $\begin{array}{l}\text { Includes clinical } \\
\text { evaluation }\end{array}$ & $\begin{array}{l}\text { Includes } \\
\text { sensory testing }\end{array}$ & $\begin{array}{l}\text { Water trial } \\
\text { procedure }\end{array}$ & Sensitivity & Specificity \\
\hline Burke dysphagia screening test & VFSS & Yes & No & $3 \mathrm{oz}$ water swallow & 88 & 22 \\
\hline Standardized swallowing assessment & VFSS & Yes & No & $\begin{array}{l}5 \mathrm{ml} \times 3 \\
\text { Cup drinking }\end{array}$ & 68 & 86 \\
\hline Timed tests of Hinds and Wiles & Symptom quest. & Yes & No & $\begin{array}{l}5-10 \mathrm{ml} \\
100-150 \mathrm{ml}\end{array}$ & 73 & 67 \\
\hline Bedside swallow assessment & VFSS/CE & Yes & No & $\begin{array}{l}5 \mathrm{ml} \times 3 \\
60 \mathrm{ml}\end{array}$ & 70 & 66 \\
\hline $\begin{array}{l}\text { Toronto bedside swallowing } \\
\text { screening test, TOR-BSST } \odot\end{array}$ & VFSS & Yes & Yes & $\begin{array}{l}5 \mathrm{ml} \text { swallow } \times 10 \\
\text { Cup sip }\end{array}$ & 91.3 & 66.7 \\
\hline Clinical examination & VFSS & Yes & No & N/A & 92 & 67 \\
\hline $\begin{array}{l}\text { Modified Mann assessment of } \\
\text { swallowing ability, MMASA }\end{array}$ & MASA & Yes & No & N/A & 93 & 86 \\
\hline
\end{tabular}

With kind permission from Springer Science+Business Media: Current Physical Medicine and Rehabilitation Reports, Dysphagia after Stroke: an Overview, 1, 2013, 187-196, González-Fernández M, Ottenstein L, Atanelov L, Christian AB, Table 2 
published tools with confirmed validity are used by 37 and $29 \%$ of practitioners, respectively [14•].

Invariably, instrumental evaluation of swallowing is used. Videofluorography (VF) is the most available and most used in North America; approximately 36 and $40 \%$ of clinical evaluations are followed by VF in Canada and the USA, respectively $[10 \bullet, 14 \bullet]$. In the US commercially available barium products are available in several consistencies for use in VF swallowing studies (Varibar). In Canada, texture preparation procedures or commercially available products are not common [10•]. The ASHA has published guidelines on the use of instrumental assessment of dysphagia [15]. Most SLPs report that thin liquid trials are important, if not essential, during VF but the use of thick liquids or solids, measures of time duration, penetration/aspiration rating, or oropharyngeal swallow efficiency is variable [13]. When surveyed, more than $90 \%$ of certified SLPs in Canada indicated that evaluation of bolus manipulation and propulsion, oropharyngeal swallow initiation, general bolus control, laryngeal motion, swallow triggering, penetration or aspiration, response to penetration or aspiration (including effectiveness of response), structural abnormalities, nasal regurgitation, and presence of bolus residue were definitely important during instrumental evaluation of swallowing [10•].

Other types of instrumental evaluation, for example fiberoptic endoscopic evaluation of swallowing (FEES) and manometry, are also used but not as commonly or consistently as VF.

\section{Management}

A recent study attempting to describe practice patterns in the USA surveyed 254 SLPs using a video-supplemented clinical case [14•]. In that study, 47 treatment techniques and 90 different treatment combinations were recommended for the same clinical case. On the basis of the case presented in this study, recommended swallowing rehabilitation techniques included (ascending order): thermal tactile application, oral bolus trials, Masako maneuver, vocal cord adduction, head turn, super supraglottic swallow, Mendelsohn maneuver, tongue base retraction, oromotor exercises, effortful swallow, laryngeal elevation exercises, Shaker exercises, and neuromuscular electrical stimulation [14•]. The same group of SLPs reported that the typical length of dysphagia therapy is approximately $30 \mathrm{~min}$ daily during which four or more therapy techniques are used.

\section{Research}

The National Institute on Deafness and other Communication Disorders (NIDCD - a part of the US National Institutes of Health) is the main body funding dysphagia research the US. Currently, 22 active proposals addressing swallowing disorders are reported by the NIH, of which $55 \%$ are funded by the NIDCD [16]. Research is being performed on several topics from basic to translational and clinical research. Research topics include, among others, screening and evaluation methods, animal models of dysphagia and nerve injury, oral sensation during swallowing, neural models of swallowing control, effects of aging on swallowing function, use of non-invasive brain stimulation for dysphagia rehabilitation, and use of manometry for diagnosis of dysphagia. The main body bringing together dysphagia researchers in North America is the Dysphagia Research Society (DRS). Although it attracts researchers from all over the world (during the last meeting 22 countries were represented) most of the delegates are from North America. Approximately $75 \%$ of the delegates at the 2013 meeting were from the US and Canada [17].

\section{The Antipodean Perspective}

The term "Antipodean" is used to casually refer to the inhabitants of New Zealand and Australia, with these countries being geographically opposite to the northern hemisphere and, more specifically, the mother country of Britain. Although this term may suite us well as we cling to the underside of the globe, its root-antipode-is not a fitting descriptor of practices in dysphagia management. Indeed, dysphagia management in this far corner of the earth is more similar to, than different from, that of colleagues in the northern hemisphere.

\section{Healthcare Funding}

Best practice in any area of medicine is not only determined by empirical research that informs of patient outcomes; it is also heavily affected by resource issues. Health care funding in New Zealand relied exclusively on a national health system until the mid to late twentieth century, with healthcare reforms resulting in a partial shift in funding to private insurance. Private health insurance is optional rather than obligatory, primarily used to bypass waiting lists associated with a national health system. A unique feature of health care in New Zealand is the government funded Accident Compensation Corporation that covers all costs associated with accidental injury for citizens, residents, and visitors. This coverage virtually eliminates personal injury legislation, including medical misadventure, because all injury is considered no-fault and receives full insurance coverage. The Australian health care system is jointly funded by government and private sector involvement, providing universal access to health care while allowing individual choice in accessing services. 
Private health insurance is encouraged and subsidized by the government and special initiatives are in place to encourage subscription to private health cover early in life.

As a point of comparison, 2011 data from The World Health Organization Global Health Expenditure database [18] reports that total health care expenditure in New Zealand amounts to $10 \%$ of the gross domestic product (GDP), with $83 \%$ of this attributed to general government expenditure. Although the Australian system is similar in total health expenditure, at $9 \%$ of GDP, the proportion attributed to government expenditure is substantially lower, at $69 \%$. In comparison, US data reveal much higher total expenditure of $18 \%$ of GDP, with government expenditure much lower at $46 \%$. These broader contextual data reflect what these authors consider to be a feature of service delivery in Australia and New Zealand: overall there may be fewer resources, but there may also be fewer restrictions on how these resources are allocated.

\section{Delivery of Care and Professional Qualifications}

Service delivery for oropharyngeal dysphagia diagnosis and management generally falls most heavily on the speech pathology profession, although, as in most regions, service delivery is supported by involvement of multidisciplinary teams. Several specialty clinics for addressing swallowing impairment through a strong medical model are scattered across both countries with large contributions by gastroenterology, otorhinolaryngology, and nursing. This model of service delivery seems consistent with that of other western countries.

\section{Professional Qualification}

Speech pathologists in Australia and New Zealand initiate clinical practice with a four-year clinical Bachelors degree or, more recently in both countries, a two-year graduate entry clinical Masters degree. The dysphagia curriculum in university programs ranges broadly from a very few hours of teaching within the context of another course (e.g. motor speech disorders) to on-line courses wherein didactic lectures are replaced by a series of tasks to be completed, to two full semester courses encompassing up to $50 \mathrm{~h}$ of didactic lectures per course. The prevalence of problem-based learning is increasing steadily as research supports this approach as a viable method for medical education [19]. In both countries, practicing clinicians are required to demonstrate entry-level competence in the diagnosis and management of pediatric and adult swallowing impairments within the framework of the competence-based standards for speech pathologists. Accreditation of University Speech Pathology programs by the relevant professional associations is dependent on adherence to these standards. A post-graduate
Master of Science in Dysphagia at a University in New Zealand that would encourage specialty multi-disciplinary training across professions is currently under consideration.

\section{Diagnosis and Management}

A recent informal survey of clinicians in Australia and New Zealand was used to confirm the authors' impressions of clinical practice patterns within these countries. Receipt of 140 responses within $48 \mathrm{~h}$ suggests that clinicians in this part of the world are interested and have invested in clinical work in this area. The range of clinicians responding to this non-scientific survey was characteristic of the presence of a few large cities (in each state of Australia and in the entirety of New Zealand), surrounded by vast rural, and slightly populated regions.

\section{Screening}

Nursing screening procedures are routinely used in hospitals as a means of referral for acute swallowing assessment in the stroke population. This has, in recent years, been strongly recommended by stroke advocacy groups and government agencies in both countries [20, 21]. However, a National Acute Stroke Audit in 2009 found only $57 \%$ of stroke patients in New Zealand were screened for swallowing before commencing oral intake [20]. The 2011 National Stroke Audit of acute services in Australia revealed a similar situation, with one-third of stroke patients not receiving swallowing screening before commencing oral intake. Patients presenting with stroke at larger hospitals were more likely to be screened for swallowing [21]. These data, combined with the emergence of data from a recent clinical trial which suggested a worryingly high incidence of pneumonia in the dysphagic stroke population [22], has resulted in an attempt to refine and standardize clinical procedures. Currently there is no standard screening procedure for identification of swallowing impairment across New Zealand or Australia, with clinicians reportedly using a variety of published and unpublished procedures. Screening procedures are currently being refined, with hopes these procedures can be standardized. One such example is the recent establishment of The Victorian Dysphagia Screening Model, which is being implemented to ensure that all patients presenting with stroke at hospitals in the Australian State of Victoria undergo standardized, evidence-based screening for swallowing before commencing oral intake [23•]. In New Zealand, a new nursing screening procedure, which incorporates cough reflex testing (CRT) as a component of the screening, has been implemented across a number of the main medical centers and is currently under evaluation for reliability and validity. The capacity to efficiently translate research into modification of clinical 
practice is a definite benefit of a somewhat small community of practitioners in this part of the world.

\section{Assessment}

Diagnosis and management of the dysphagic patient in the acute hospital seems consistent with international trends. Dysphagia management services are routinely provided for care of patients across diagnostic etiologies, including both pediatric and adult populations, and in general medical wards, specialized diagnostic units, and intensive-care units. Services may be continued through outpatient clinics and home-based community clinical teams that service chronic care facilities. Referrals to speech language pathology are generated most frequently as ad hoc referrals by physicians or other members of the multidisciplinary team, or as the result of routine screening for swallowing impairment on admission.

Clinical swallowing evaluation (CSE) continues to be the basis of evaluation practices. This assessment consists primarily of evaluation of cranial nerve function and observation of oral ingestive behavior. Less routinely, the CSE includes formal cognitive communication screening, CRT, cervical auscultation, and pulse oximetry. Quantitative measures such as the timed test of swallowing (TTS) [24] and the test of mastication and swallowing of solids (TOMASS; authors' data pending publication) are used inconsistently and at a limited number of facilities. Use of the CRT, TTS, and TOMASS seems more frequent in New Zealand, because of local research being undertaken in this area. Videofluoroscopic swallowing study (VFSS) is the most frequently executed instrumental diagnostic examination and is fairly readily available in most urban areas. Position papers by the New Zealand [25•] and Australian [26] professional associations support completion of the VFSS by the speech pathologist and radiographer only, with the caveat that a qualified radiologist is available to review the examination if questions are raised regarding anatomy. This has enabled greater flexibility in scheduling examinations given radiology resource constraints. Given the rural nature of both countries, however, the VFSS continues to be difficult to access in smaller facilities with clinicians relying on CSE for management decisions. Although videoendoscopic evaluation of swallowing (VEES) is increasing, this technique is used by speech pathologists for dysphagia assessment in approximately $15 \%$ of facilities only. Pharyngeal manometry and ultrasound are very rarely used routinely, with application limited to specialist clinics.

\section{Management}

Management of the dysphagic patient is varied, with clear evidence that leading clinicians are keeping abreast of emerging trends in practice, although new techniques are not yet practiced routinely. Compensatory management of swallowing impairment continues to lead the way with a heavy reliance on diet modification. Structured oral hygiene programs for patients with swallowing impairment are not common, although most regard it as an important part of patient care. In most settings, this basic care is provided most frequently by nursing staff. There is increased recognition of the role of oral hygiene in reducing risk of pulmonary compromise, with research in progress in New Zealand to investigate this more carefully among the stroke population.

Rehabilitation practices are, in most cases, primarily limited to execution of neuromuscular exercises without the use of exteroceptive biofeedback. For clinicians who provide rehabilitation services, intensive treatment in up to five sessions weekly is frequently scheduled, however this treatment is not necessarily direct face-to-face contact and may reflect home programming recommendations. This is likely to reflect the more adaptable nature of national healthcare systems with less emphasis on funding issues. Lee Silverman voice training is infrequently implemented and expiratory muscle strength training has barely entered clinical practice. A notable difference from other countries, neuromuscular electrical stimulation has not entered routine clinical practice in these two countries. The professional organizations for speech pathologists in both countries have ratified position papers that currently discourage the use of this treatment approach in routine clinical practice and promote limiting its implementation to research contributing to the evidence base until further research becomes available to ensure safety and treatment effect [27, 28••, 29]. Neuromodulatory brain stimulation techniques, for example transcranial magnetic stimulation or transcranial direct current stimulation, have also not yet moved into clinical practice in these countries [30].

\section{Research}

In both countries, a vibrant multi-disciplinary research community addresses questions in basic and clinical science. Research on adult and pediatric patients is being conducted to investigate all facets of dysphagia diagnosis and management, including the development and implementation of novel screening and intervention, investigation of the neural basis of healthy and impaired swallowing, nutritional and social aspects of dietary intake, and evaluation and improvement of current best practice. Despite increasing limitations in research funding and challenges imposed by geographical distance and research infrastructure, research conducted in Australia and New Zealand meets high scientific standards and is consistently presented at international scientific meetings and published in peer-reviewed journals. For example, in the last decade research abstracts submitted 
by Australian and New Zealand research groups constituted nearly $6 \%$ of presentations at the Annual Meetings of the Dysphagia Research Society [31].

In summary, the community of clinicians and researchers committed to the ever-progressing development of best practice for patients with swallowing impairment is alive and well in the Antipodes. As academic programs expand, a greater number of research-trained clinicians will emerge in the region, ensuring continuing improvements in service delivery through reflective clinical practice and clinically relevant research. The relatively small population of clinicians and national health systems enables fairly rapid integration of clinical research into the provision of evidencedbased diagnostic and management services. The relative "youth" of both countries is evident only in the enthusiasm of the search for best practice.

\section{An Asian Perspective: Japan}

Aging is a looming threat in Japan. The total population is decreasing, and people aged 65 or older will comprise $39.4 \%$ of the Japanese population by 2055 [32]. In these circumstances, dysphagia-related deaths have been increasing. Pneumonia is the third cause of the death overall and the leading cause of death for people 85 years of age or older [33]. Approximately $60 \%$ of elderly patients admitted to hospitals with pneumonia were reported to have aspirationrelated pneumonia [34•]. Moreover, asphyxiation accounts for a high proportion of "freak accidents", the fifth cause of death in Japan. According to a 2012 study, patients with dysphagia represent $13.8,31.6$, and $59 \%$ of patients in general hospitals, rehabilitation hospitals, and long-term care hospitals respectively [35••]. Because aspiration pneumonia and asphyxiation are closely related to dysphagia, dysphagia rehabilitation and treatment has become very important in Japan.

\section{Healthcare Funding}

Japan's health indices, for example life expectancy at birth, are among the best in the world, but the proportion of GDP spent on health $(8.5 \%)$ was 20th among Organization for Economic Co-operation and Development countries in 2008 and half as much as that in the US [36]. Japan has achieved good population health at low cost. Universal coverage started in 1961 and virtually all Japanese people are covered by social health insurance, through 3,500 plans which depend on where they are employed or where they reside [37]. Patients usually pay $30 \%$ of medical costs, but elderly people aged 75 or older pay $10 \%$. In addition, medical subsidy is provided for people in financial hardship, people with disabilities, infants, and children.
Moreover, the monthly burden of individual medical care expenses is limited to a fixed sum. However, any rehabilitation, including dysphagia, is time-limited for cost containment. For example, stroke rehabilitation is covered by medical insurance for 180 days after onset.

\section{Delivery of Care and Professional Qualification}

Speech-language-hearing therapists (SLHT) are the main practitioners providing direct treatment for dysphagia. The national licensing system of SLHT in Japan was established by law in 1997, and the first national license exam was administered by the Ministry of Health, Labor, and Welfare in 1999. Education for SLHT is offered at the post-high school level at universities, institutes for college graduates, and institutes for high-school graduates. Dysphagia is a compulsory subject in the curriculum, and ranges from 30 to $60 \mathrm{~h}$. In addition to SLHT, many medical professions are involved in the dysphagia rehabilitation team including physicians, dentists, nurses, physical therapists, occupational therapists, dental hygienists, dieticians, and social workers. In Japan, participation of dentists in dysphagia rehabilitation is high, dentists providing expertise particularly in dental prostheses and oral care. However, there are still a small number of healthcare settings in which all disciplines are available to engage in the rehabilitation of patients.

Thus, transdisciplinary teamwork models, in which the patient's presenting needs are treated by the available medical practitioners and tasks are assigned, is common in Japan. The composition of a team determines the roles and responsibilities of each practitioner. Because the role of each practitioner is not fixed, the team needs to hold and share fundamental clinical objectives and procedural pathways that are jointly executed by the individual team members, complementary to the formal expertise, knowledge, and skills of each member. To accomplish this, the Japanese Society of Dysphagia Rehabilitation was established in 1994 [38] and now has more than 10,000 members (Fig. 1). In 2009, the Society started an e-learning and practitioner certification system to standardize and expand the knowledge of practitioners.

An example of the transdisciplinary approach is the dysphagia rehabilitation team at Fujita Health University. The swallowing team comprises dysphagia-certified nurses, physiatrists, dentists, SLHTs, dental hygienists, dieticians, and ward nurses who participate in swallowing rounds three times a week. Certified nurses are of crucial importance in the team because they are closely evaluating patients constantly. Dysphagia treatment is performed by SLHTs and ward nurses. Physiatrists or dentists perform VEES during rounds, as needed, and team members discuss and decide on appropriate diet and treatment recommendations. 


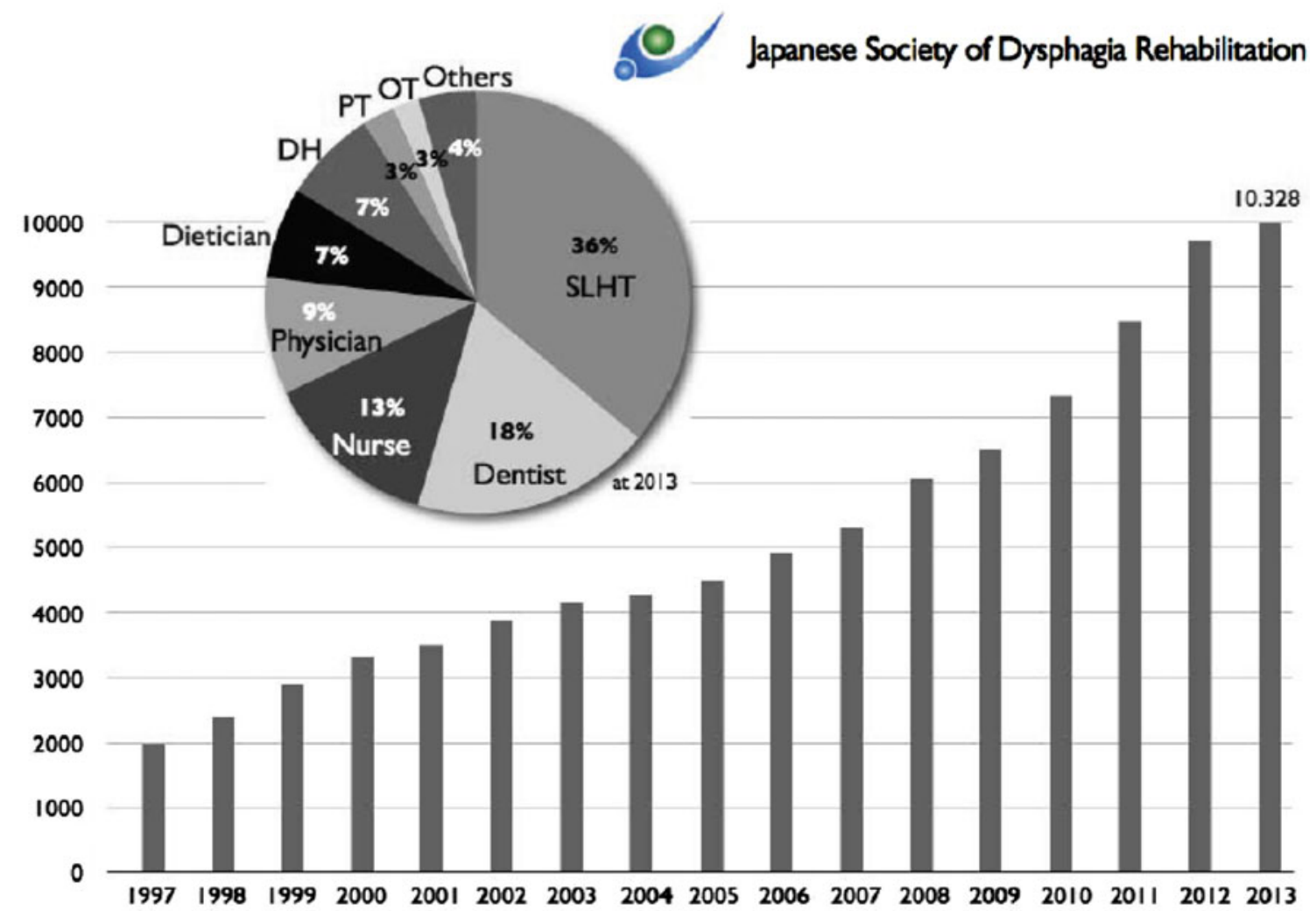

Fig. 1 Membership of the Japanese Society of Dysphagia Rehabilitation (JSDR) and constitution of the members/JSDR is a transdisciplinary society established in 1995 . Members have been constantly increasing and it was up to 10,328 in 2013 . With kind permission from the Japanese Society of Dysphagia Rehabilitation for reproduction of this material. SLHT speech-language-hearing therapist, $D H$ dental hygienist, $P T$ physical therapist, $O T$ occupational therapist
Diagnosis and Management

\section{Screening}

Several screening tests for detecting dysphagia are used in Japan. These are followed by clinical evaluation and instrumental evaluation, for example VE or videofluoroscopic (VF) examination of swallowing when suspected dysphagia is identified by screening.

During the repetitive saliva swallowing test (RSST) patients are instructed to perform saliva (dry) swallows as many times as possible in $30 \mathrm{~s}$. Fewer than three swallows in $30 \mathrm{~s}$ is regarded as abnormal. The sensitivity and specificity of the RSST to detect aspiration as diagnosed by VF are 0.98 and 0.66 , respectively [39, 40॰].

Two water-swallowing tests are commonly used in Japan-the $30 \mathrm{ml}$ water-swallowing test and the modified water-swallowing test (MWST). In the first of these tests the patient is asked to swallow $30 \mathrm{ml}$ of room temperature water from a cup. Number of swallows and coughing are scored by use of a five-point scale; other behavior during swallowing (sipping, leakage from lips, etc.) is recorded
[41]. The MWST assesses swallowing and aspiration: $3 \mathrm{ml}$ cold water is placed in the mouth by use of a syringe and patients are instructed to swallow followed by two saliva swallows. Breathing, coughing, and voice quality are scored by use of a five-point scale. Sensitivity and specificity for detection of aspiration, as diagnosed by VF, are 0.70 and 0.88 , respectively, when the cut off score is 3 [42].

The $4 \mathrm{~g}$ pudding test is used to screen for solid food dysphagia. Administration and scoring are nearly identical to those for the MWST procedure. The pudding is placed on the dorsum of the tongue, by use of a spoon, and the patient is instructed to swallow. In addition to breathing, cough, and voice quality, oral residue is also evaluated. Sensitivity and specificity of this screening test for detection of aspiration, as diagnosed by VF, are 0.72 and 0.62 , respectively, when the cut off score is 4 [42].

The simple two-step swallowing-provocation test (STSSPT) is used to assess swallowing response time. Distilled water is injected into the suprapharynx of patients, in supine position, thorough a nasal catheter. The first step is a $0.4 \mathrm{ml}$ injection followed by a $2.0 \mathrm{ml}$ second step. The time from water injection to the onset of swallowing is 
measured. A mean of $3 \mathrm{~s}$ or more is considered abnormal. Sensitivity and specificity of the STS-SPT for detection of patients with aspiration pneumonia have been reported to be 1.00 and 0.83 , respectively, for the first-step and 0.67 and 1.00, respectively, for the second step [43].

The cough test is used to assess airway protection. Patients orally inhale a $1 \%(w / v)$ mist of citric acidphysiological saline by use of a nebulizer. Coughing four times or less is regarded as indicative of silent aspiration. Sensitivity and specificity of this test for detection of silent aspiration, as diagnosed by VE, were 0.87 and 0.89 , respectively. A simplified cough test with a portable nebulizer has been developed. Absence of a cough in the first $30 \mathrm{~s}$ from the start of inhalation is an indicator of silent aspiration. Sensitivity and specificity of detection of silent aspiration, as diagnosed by $\mathrm{VE}$, were 0.92 and 0.94 , respectively. The cough test can be performed on patients who have difficulty following instructions. Combining the cough test and MWST has been reported to increase detection of silent aspiration [44].

Because these tests are less invasive and do not need expensive instruments, they are frequently used to evaluate swallowing function and changes in function. The RSST is recommended in the basic checklist of the preventive care medical checkup by the Ministry of Health, Labor and Welfare for people over 65 years old [45]. In addition, the RSST is useful for detection of dysphagia associated with exacerbation in patients with chronic obstructive pulmonary disease [46].

\section{Assessment}

Physicians, SLHT, and nurses perform clinical diagnosis of dysphagia in Japan. Guidelines for evaluation have been proposed by the Japanese Society of Dysphagia Rehabilitation [47]. The guidelines suggest a minimum of eight items for clinical evaluation:

1 cognition;

2 observation of eating;

3 range of motion of head and neck;

4 dental prosthesis and oral hygiene;

5 oral motor and sensory examination;

6 phonation and articulation;

7 pulmonary function; and

8 nutrition and hydration.

$\mathrm{VF}$ and VE are performed if further evaluation is necessary. According to the clinical evaluation, with etiology, general state, and/or the instrumental diagnosis, severity of dysphagia is evaluated with the Dysphagia Severity Scale [48] or the Food Intake LEVEL Scale (FILS) [49] to furnish information on which to base treatment decisions and objectives.

\section{Management}

Usual rehabilitation techniques in Japan include: chin down, head turn, reclining position, thermal tactile application, K-point stimulation, Masako's maneuver, supraglottic swallow, super supraglottic swallow, Mendelsohn maneuver, effortful swallow, and Shaker exercises [50]. In addition, the need and importance of appropriate oral care has been recognized as essential. Oral care is sometimes the main and only intervention for swallowing rehabilitation in understaffed hospitals and institutions. The Japanese Dental Association has worked to promote the commitment of dentists and dental hygienists to active intervention in oral care for disabled people. Dentists and dental hygienists also teach essential oral care to patients, caregivers, and other practitioners and promote the use of oral care every day after each meal. Formal studies of disabled elderly nursing home populations have revealed that oral care reduced the incidence of pneumonia [51, 52•].

Food texture modification methods have been developed and commercialized in Japan. Most recently, iEat products (EN Otsuka, Hanamaki, Japan) has been attracting attention [53]. By use of the enzyme homogeneous permeation technique, food texture can be precisely designed and modified. As an example, the hardness of a beef steak is converted from 160.4 to $5.3\left(10^{4} \mathrm{~N} / \mathrm{m}^{2}\right)$ and adhesiveness is converted from 295.1 to $1.2\left(10^{2} \mathrm{~J} / \mathrm{m}^{3}\right)[23 \cdot]$. These changes are made while maintaining the usual appearance of the food being modified. Clinical availability of a variety of modified but familiar foods improves patients' quality of life.

Laryngeal suspension surgery has been used after some cancers of the tongue, larynx, and pharynx. In Japan, this type of surgery is also used for severe dysphagia (not due to cancer). The thyroid cartilage, hyoid bone, and/or mandible are sutured by use of thread or wire. Pulling the larynx upward and forward is accompanied by strengthening of the laryngeal elevation, facilitating closure of the laryngeal vestibule and opening of the upper esophagus sphincter (UES). Patients are trained to use a head extension and neck flexion posture to open the UES after the surgery. A cricopharyngeal myotomy is often performed simultaneously.

Research

Several basic to clinical research topics are being evaluated in Japan. These include electrical stimulation, transcranial magnetic stimulation, tongue pressure, manometry, etc. One advance in the past five years is research using a 320-row area detector CT (320-ADCT) [55, 56]. The advantage of visualization of swallowing motion, with continuous three-dimensional images, and the possibility of quantification, enable precise kinematic analysis of 
swallowing. As for temporal analysis of swallowing, the effect of bolus viscosity on laryngeal closure was reported in 2012 [57], and, most recently, in 2013 an analysis of hyoid muscle length with the trajectory of the hyoid bone was reported [58].

\section{Conclusion}

These three perspectives on the care, evaluation, and management of swallowing dysfunction are more similar than they are different. Nonetheless, differences in practice patterns between regions of the world are evident. Collaboration in research of different areas of the world has the potential to significantly enrich knowledge and help develop best-practice models. Irrespective of the region of the world, it is evident that much attention is devoted on the care of people with swallowing dysfunction and that all involved are committed to improving their function and participation in society.

Acknowledgments Marlís González-Fernández - Grant funds support from the National Institutes of Health -1K23DC01156

\section{Compliance with Ethics Guidelines}

Conflict of Interest Marlís González-Fernández, Maggie-Lee Huckabee, Sebastian H. Doeltgen, Yoko Inamoto, Hitoshi Kagaya and Eichii Saitoh declare that they have no conflict of interest.

Human and Animal Rights and Informed Consent This article does not contain any studies with human or animal subjects performed by any of the authors.

\section{References}

Papers of particular interest, published recently, have been highlighted as:

- Of importance

•• Of major importance

1. Casper ML, Barnett E, Williams GI Jr, Halverson JA, Braham VE, Greenlund KJ. Atlas of stroke mortality: racial, ethnic, and geographic disparities in the United States; 2003.

2. Howard G. Why do we have a stroke belt in the southeastern United States? A review of unlikely and uninvestigated potential causes. Am J Med Sci. 1999;317(3):160-7.

3. Physical therapy/occupational therapy/speech-language pathology services; 2013. http://www.medicare.gov/coverage/pt-andot-and-speech-language-pathology.html. Accessed Sept 2013.

4. Affordable care act; 2013. http://www.hhs.gov/opa/affordablecare-act/. Accessed Sept 2013.

5. Larsen GL. Rehabilitation for dysphagia paralytica. J Speech Hear Disord. 1972;37(2):187-94.

6. Logemann J. Evaluation and treatment of swallowing disorders. Austin: Pro-Ed; 1983.
7. Roles of speech-language pathologists in swallowing and feeding disorders: technical report. 2001. http://www.asha.org/policy/ TR2001-00150/. Accessed Sept 2013.

8. CASLPA - position paper on dysphagia in adults. 2007. http:// www.caslpa.ca/PDF/position\%20papers/English_Dysphagia_June\% 202007.pdf. Accessed Sept 2013.

9. Disease-specific care certification Program STROKE performance measurement implementation guide, 2nd edition, version 2.a. 2008. http://www.jointcommission.org/assets/1/18/stroke_ pm_implementation_guide_ver_2a.pdf. Accessed Sept 2013.

10. - Martino R, Pron G, Diamant NE. Oropharyngeal dysphagia: surveying practice patterns of the speech-language pathologist. Dysphagia. 2004;19(3):165-76. This article presents the results of a practice patterns survey of speech language pathologists in Canada.

11. - Steele CM, Allen C, Barker J, Buen P, French R, Fedorak A, et al. Dysphagia service delivery by speech-language pathologists in Canada: results of national survey. Can J Speech Lang Pathol Audiol. 2007;31(4):166-77. This article presents the results of a service delivery survey of speech language pathologists in Canada.

12. - Mathers-Schmidt BA, Kurlinski M. Dysphagia evaluation practices: Inconsistencies in clinical assessment and instrumental examination decision-making. Dysphagia. 2003;18(2):114-25. Inconsistencies in clinical assessment and instrumental examination of dysphagia are described.

13. McCullough GH, Wertz RT, Rosenbek J, Dinneen C. Clinicians' preferences and practices in conducting clinical/bedside and videofluoroscopic swallowing examinations in an adult, neurogenic population. Am J Speech Lang. 1999;8:149-63.

14. - Carnaby GD, Harenberg L. What is "usual care" in dysphagia rehabilitation: a survey of USA dysphagia practice patterns. Dysphagia. 2013. ePub ahead of print. doi:10.1007/s00455-0139467-8. This article presents the results of a survey of dysphagia care practice patterns in the USA.

15. American Speech-Language-Hearing Association. Clinical indicators for instrumental assessment of dysphagia [guidelines]. 2000. www.asha.org/policy/GL2000-00047/. Accessed Sept 2013.

16. NIH research portfolio online reporting tools. http://project reporter.nih.gov/reporter.cfm. Accessed Sept 2013.

17. Final attendee list 2013. http://www.dysphagiaresearch.org/index. php/members/highlights-from-past-meetings. Accessed Sept 2013.

18. World Health Organization. Global Health Expenditure Database. http://apps.who.int/nha/database/PreDataExplorer.aspx?d=1. Accessed June 2013.

19. Koh GC, Khoo HE, Wong ML, Koh D. The effects of problembased learning during medical school on physician competency: a systematic review. CMAJ. 2008;178(1):34-41.

20. Stroke Foundation of New Zealand. National acute stroke services audit 2009. Wellington, New Zealand: Stroke Foundation of New Zealand. http://www.stroke.org.nz/resources/SFNZ-NASSA2009.pdf. Accessed June 2013.

21. National Stroke Foundation of Australia. National Stroke AuditAcute Services Clinical Audit Report. 2011. http://strokefounda tion.com.au/health-professionals/clinical-guidelines/acute-audit/. Accessed June 2013.

22. Miles A, Zeng IS, McLauchlan H, Huckabee ML. Cough reflex testing in dysphagia following stroke: a randomized controlled trial. J Clin Med Res. 2013;5(3):222-33.

23. - Department of Health, Victoria. The Victorian Dysphagia Screening Model: The Assist Dysphagia Screening Tool. http:// health.vic.gov.au/clinicalnetworks/stroke/dysphagia.htm. Accessed June 2013. Recommended dysphagia screening tools in Australia are described.

24. Hughes TA, Wiles CM. Clinical measurement of swallowing in health and in neurogenic dysphagia. QJM. 1996;89(2):109-16. 
25. • Miles A., Benoit, A., Keesing, M., McLauchlan, H., et al. (2010) New Zealand Speech-language Therapy Clinical Practice Guideline on Videofluoroscopic Study of Swallowing (VFSS) 2010. New Zealand Speech-language Therapy Association (NZSTA), Available at http://www.speechtherapy.org.nz/info-SLTs/guidelines. position.papers/VFSS. Accessed June 2013. New Zealand's clinical practice guidelines on the videofluorographic study of swallowing are described.

26. Speech Pathology Australia. Speech Pathology Australia position statement: Modified Barium Swallow. 2005. http://www.speech pathologyaustralia.org.au/library/Clinical_Guidelines/Dysphagia_ MBS.pdf. Accessed June 2013.

27. Speech Pathology Australia. Speech Pathology Australia position statement: Neuromuscular Electrical Stimulation in dysphagia and related disorders.2008. http://www.speechpathologyaustralia.org. au/library/position_statements/Neuromuscular_Electrical_Stimula tion_NMES_Position_Statement.pdf. Accessed June 2013.

28. • Huckabee ML, Doeltgen S. New Zealand Speech-language Therapy Position Paper on Neuromuscular Electrical Stimulation in Swallowing Rehabilitation 2007. New Zealand Speech-language Therapy Association (NZSTA), Available at http://www. speechtherapy.org.nz/infoSLTs/guidelines.position.papers/Estim \%20position\%20paper.doc/view Accessed June 2013. This article is New Zealand's position statement on the use of neuromuscular electrical stimulation in Dysphagia.

29. Huckabee ML, Doeltgen SH. Emerging modalities in dysphagia rehabilitation: neuromuscular electrical stimulation. N Z Med J. 2007;120(1263):1-9.

30. Doeltgen SH, Huckabee ML. Swallowing neurorehabilitation: from the research laboratory to routine clinical application. Arch Phys Med Rehabil. 2012;93:207-13.

31. Plowman EK, Mehdizadeh O, Leder SB, Martino R, et al. A bibliometric review of published abstracts presented at the Dysphagia Research Society: 2001-2011. Dysphagia. 2013;28:123-30.

32. Population survey report by Ministry of Health, Labour and Welfare. http://www.mhlw.go.jp/seisakunitsuite/bunya/hukushi_kaigo/kaigo_ koureisha/chiiki-houkatsu/dl/link1-1.pdf. Accessed Jan 2013.

33. Population survey report by Ministry of Health, Labour and Welfare. http://www.mhlw.go.jp/toukei/saikin/hw/jinkou/suikei12/dl/ hon bun.pdf. Accessed January 2013.

34. - Teramoto S, Fukuchi Y, Sasaki H, et al. High incidence of aspiration pneumonia in community-and hospital-acquired pneumonia in hospitalized patients: a multicenter, prospective study in Japan. J Am Geriatr Soc. 2008;56:577-9. This study highlights that there is high prevalence of dysphagia in long term care hospitals.

35. • Saitoh E. Investigation of distribution of dysphagic patients using Dysphagia Severity Scale. Report of a project of enhancing heath care of the aged [investigational project of dysphagia]. 2012. This study highlights that, in Japan, a high proportion of elderly patients admitted to hospitals with pneumonia have aspiration pneumonia.

36. Hashimoto H, Ikegami N, Shibuya K, et al. Cost containment and quality of care in Japan: is there a trade-off? Lancet. 2011;378: 1174-82.

37. Shibuya K, Hashimoto H, Ikegami N, et al. Future of Japan's system of good health at low cost with equity: beyond universal coverage. Lancet. 2011;378:1265-73.

38. The Japanese Society of Dysphagia Rehabilitation: about JSDR. http:// www.jsdr.or.jp/english/english_about.html. Accessed Sept 2013.

39. Oguchi K, Mizuno M, Baba M, et al. The repetitive saliva swallowing test (RSST) as a screening test of functional dysphagia (1) normal values of RSST. Jpn J Rehabil Med. 2000;37:375-82.

40. - Oguchi K, Baba M, Kusudo S, et al. The repetitive saliva swallowing test (RSST) as a screening test of functional dysphagia (2) Validity of RSST. Jpn J Rehabil Med. 2000;37:383-8. This article described the repetitive saliva swallowing test and its high sensitivity to detect aspiration.

41. Kubota T. Dysphagia after stroke-Screening test and clinical application. Sogo Rehabil. 1982;10:271-6.

42. Saitoh E. 2009 Grant for Ministry of Welfare (Comprehensive Gerontologic Science) Comprehensive study of treatment and management for dysphagia. Report of Grant for Ministry of Welfare. 2009;1999:1-18.

43. Teramoto S, Matsuse T, Fukuchi Y, Ouchi Y. Simple two-step swallowing provocation test for elderly patients with aspiration pneumonia. Lancet. 1999;353:1243.

44. Wakasugi Y, Tohara H, Hattori F, et al. Screening test for silent aspiration at the bedside. Dysphagia. 2008;23:364-70.

45. Suzuki T. Manual of life functional assessment for preventive care. http://www.mhlw.go.jp/topics/2009/05/dl/tp0501-1c_0001. pdf. Accessed Sept 2013.

46. Tsuzuki A, Kagaya H, Takahashi H, et al. Dysphagia causes exacerbations in individuals with chronic obstructive pulmonary disease. J Am Geriatr Soc. 2012;60:1580-2.

47. Ueda K, Okada S, Kitazumi E, et al.. Evaluation for dysphagia (a simplified version). Proposal from Medical committee in the Japanese Society of Dysphagia Rehabilitation. JJDR. 2011;15:96-101.

48. Baba M, Saitoh E. Indication of dysphagia rehabilitation. Rinsho Reha. 2000;9:857-63.

49. Kunieda K, Ohno T, Fujishima I, et al. Reliability and validity of a tool to measure the severity of dysphagia: the food intake level scale. J Pain Symptom Manage. 2013;46:201-6.

50. Fujishima I, Ueda K, Okada S, et al. Rehabilitation techniques for dysphagia (revised 2010). JJDR. 2010;14:644-63.

51. Yoneyama T, Yoshida M, Ohrui $\mathrm{T}$, et al. Oral care reduces pneumonia in older patients in nursing homes. J Am Geriatr Soc. 2002;50:430-3.

52. - Yoneyama $\mathrm{T}$, Yoshida $\mathrm{M}$, Matsui $\mathrm{T}$, et al. Oral care and pneumonia. Oral Care Working Group. Lancet. 1999;354:515. This article highlights that oral care reduces the incidence of pneumonia in nursing home patients.

53. iEat by EN Otsuka Pharmaceutical Company. http://www.ieat.jp/ point/softness.html. Accessed Sept 2013.

54. Higashiguchi T. Development of the shape-maintaining and softened meals iEat, and evaluation of its degradability and digestibility by the analysis of texture, ingredient and artificial digestion. J Jpn Soc Parenter Enteral Nutr. 2011;26:95-106.

55. Fujii N, Inamoto Y, Saitoh E, et al. Evaluation of swallowing using 320-detector-row multislice CT. Part I: single- and multiphase volume scanning for three-dimensional morphological and kinematic analysis. Dysphagia. 2011;26:99-107.

56. Inamoto Y, Fujii N, Saitoh E, et al. Evaluation of swallowing using 320-detector-row multislice CT. Part II: kinematic analysis of laryngeal closure during normal swallowing. Dysphagia. 2011;26:209-17.

57. Inamoto Y, Saitoh E, Okada S, et al. The effect of bolus viscosity on laryngeal closure in swallowing: kinematic analysis using 320-row area detector CT. Dysphagia. 2013;28:33-42.

58. Okada T, Aoyagi Y, Inamoto Y, et al. Dynamic change in hyoid muscle length associated with trajectory of hyoid bone during swallowing: analysis using 320-row area detector computed tomography. J Appl Physiol. 2013;115:1138-45. 